\title{
A CASE OF RHEUMATIC MITRAL REGURGITATION AND PERSISTENT DUCTUS ARTERIOSUS
}

\author{
BY \\ H. R. S. HARLEY AND A. G. WATKINS
}

From the United Cardiff Hospitals

This case is reported because of the unique association of lesions, the diagnostic and therapeutic problems raised, and the remarkable benefit conferred by simple ligation of the large persistent ductus arteriosus.

\section{Case History}

A girl aged 17 years had a history of whooping cough and pneumonia when she was two years of age. The heart was said to be affected at that time. In August, 1950, she had an attack of acute rheumatism and in the following January she was admitted to the Sandbrook House Rheumatic Hospital School at Merthyr. She remained there for nine years, having further attacks of rheumatism with arthritis, carditis and nodules. The sedimentation rate was raised for most of the time. The patient was intermittently afflicted with pericarditis, dyspnœa, joint pains and loss of weight; there were episodes of heart failure, causing enlargement of the liver and basal crepitations but no œdema. During the last year there her general condition improved and active infection apparently ceased. She remained severely disabled, being dyspnœic even when dressing and talking; indeed she was slightly breathless at rest. From time to time there was palpitation on excitement, cyanosis of the lips and transient bouts of giddiness although there was never syncope.

In view of her general improvement and the subsidence of active rheumatism, it was thought that further investigations were indicated, with a view to assessing the possibility of surgical help. She was accordingly transferred to Llandough Hospital.

Clinical Examination. On admission to Llandough Hospital on 29/5/58 the patient weighed only 6 stone $2 \frac{3}{4} \mathrm{lb}$. She was of small stature and had a moderate kyphoscoliosis which was considered to be congenital. Although there was no cyanosis she had a grade 3 mitral facies. The jugular venous pressure was normal and no enlargement of the liver or œdema of the ankles was present. The pulse was regular, full, collapsing and of moderate tension. The arterial pressure was 130/70. The cardiac impulse was of left ventricular type. There was no parasternal thrust but a lifting impulse (grade 1) was felt at the epigastrium and also over the pulmonary artery. At the mitral area a diastolic murmur and thrill (grade 3 ) were observed. The mitral first sound was soft; an apical systolic murmur (grade 3) was audible and a possible third heart sound. There was no opening snap. The second sound at the pulmonary area was split, but not accentuated. A rumbling continuous murmur was heard maximally at the first left intercostal space. No aortic murmurs were present. There was diminution of expansion and of air entry on the left side of the chest, but the percussion note was resonant, and the breath sounds were vesicular with no added sounds.

Radiological Examinations. The right lung was pleonæmic whereas the left was oligæmic (Fig. 1). The right root shadow showed enlargement of an arterial type, whereas that on the left side was absent. Considerable enlargement of the heart and left ventricle was seen, with possible slight enlargement of the right ventricle. There was much enlargement of the pulmonary artery, but the aorta was small. The left atrium was moderately enlarged. Scoliosis of the mid-dorsal region produced convexity of the spine to the right.

Electrocardiography. The electrocardiogram showed patterns denoting a vertical heart with no axis deviation. Sinus rhythm was present. There were indications of left atrial hypertrophy and left ventricular strain, but no evidence of right ventricular hypertrophy in the præcordial leads. The mean spatial QRS vector was directed vertically downwards and slightly backwards.

Phonocardiography. This showed pansystolic and presystolic mitral murmurs, and a continuous murmur at the pulmonary area. 


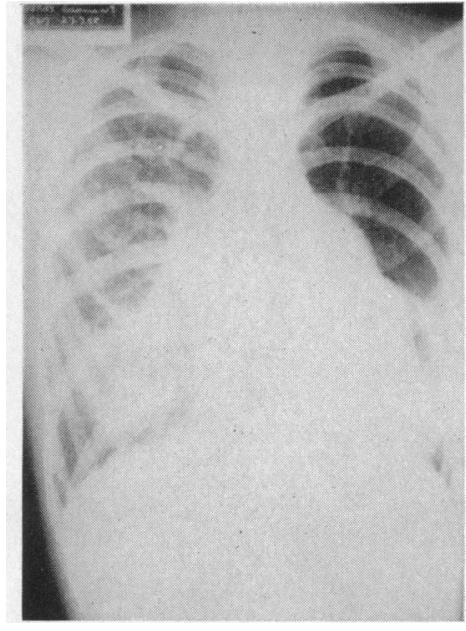

FIG. 1.-Considerable enlargement of the heart, the left atrium and the pulmonary artery and its right branch, with marked pleonæmia of the right lung, and severe oligæmia of the left lung.

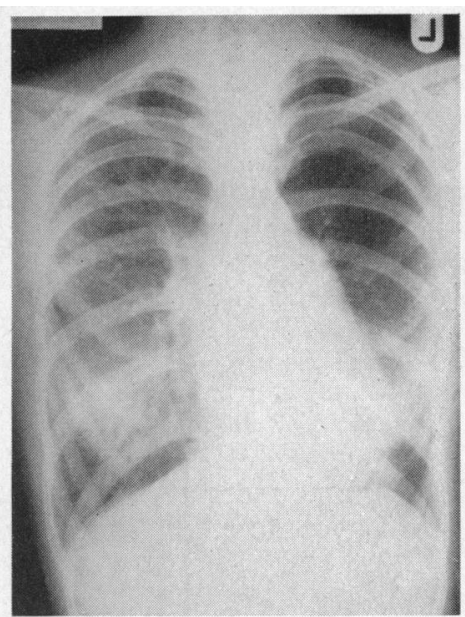

FIG. 2.-Marked reduction in size of the heart, left auricle, and pulmonary artery and its right branch, and in degree of pleonæmia of right lung two years after operation.

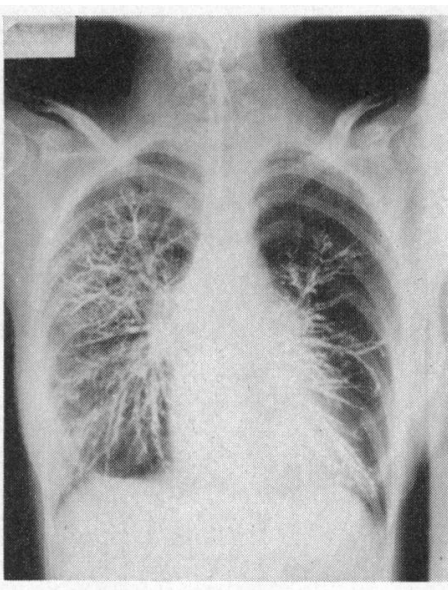

FIG. 3.-Absence of filling of ter minal branches of left bronchia tree with slight dilatation and irregularity of segmental and smaller bronchi.

Cardiac Catheterization. The catheter was passed by way of the median basilic vein to the right atrium, right ventricle and main pulmonary artery, but it could not be passed into the right pulmonary artery. The aorta was not entered.

\begin{tabular}{|c|c|c|c|c|}
\hline & & & Pressure & Oxygen content \\
\hline $\begin{array}{l}\text { R.A. } \ldots \\
\text { R.V. . . } \\
\text { P.A. } \quad \cdots\end{array}$ & $\begin{array}{l}\ldots \\
\ldots \\
\ldots\end{array}$ & $\begin{array}{l}\ldots \\
\ldots \\
\ldots\end{array}$ & $\begin{array}{l}9 / 0 \mathrm{~mm} . \mathrm{Hg} \\
44 / 0 \quad, \\
39 / 28,\end{array}$ & $\begin{array}{l}13.4 \text { vols per cent } \\
13.48 \% \\
15.27 \%\end{array}$ \\
\hline
\end{tabular}

It was concluded that there was a persistent ductus arteriosus with considerable left-to-right shunt.

The Therapeutic Problem. The girl was so disabled that treatment, if feasible, seemed to be imperative. It was considered that the persistent ductus arteriosus was causing severe disability partly by producing an important left-to-right shunt, and so increasing the work of the left ventricle, and partly by increasing the degree of incompetence resulting from the mitral valve disease, because of the strain it was imposing on the left ventricle. It was therefore hoped that closure of the ductus might not only eliminate the left-to-right shunt, but also reduce the degree of mitral incompetence and so confer a double benefit upon the left ventricle.

Findings at Thoracotomy. Left thoracotomy, with ligation of the persistent ductus arteriosus, and exploration of the mitral valve, the left pulmonary artery and its branches, and the left lung was performed on 30/7/58. Universal pleural adhesions were present. The left upper lobe was voluminous, emphysematous and almost devoid of pigment. The left lower lobe was small, of more or less normal texture, and completely devoid of pigment. Both lobes inflated well and neither was collapsed. The pericardium was totally adherent. The heart was hyperkinetic and moderately enlarged. There was moderate enlargement of the left ventricle and slight enlargement of the right ventricle. The pulmonary artery and its right branch were very big, being at least twice the normal size. The aorta looked normal, and there was moderate enlargement of a hyperkinetic left atrium. While there was a mitral systolic thrill, systolic expansion of the left atrium could not be elicited. The transverse sinus was obliterated. There was a large persistent ductus arteriosus $1 \mathrm{~cm}$. wide 
and $1 \mathrm{~mm}$. long, almost of window type. A powerful thrill was felt over this and over the pulmonary artery back to the pulmonary valve. Compression of the ductus eliminated the thrill. Despite the very large size of the main pulmonary artery and its right branch, the left pulmonary artery rapidly narrowed in a conical manner to a vessel of only about one half of the calibre of a normal left pulmonary artery. This vessel then divided into two small branches, one for each lobe, that to the lower lobe being very much smaller than normal. The left pulmonary artery and its branches had a lumen and showed no evidence of previous thrombosis. The following pressures in $\mathrm{mm}$. $\mathrm{Hg}$ were recorded by direct needle puncture before and after ligation of the ductus.

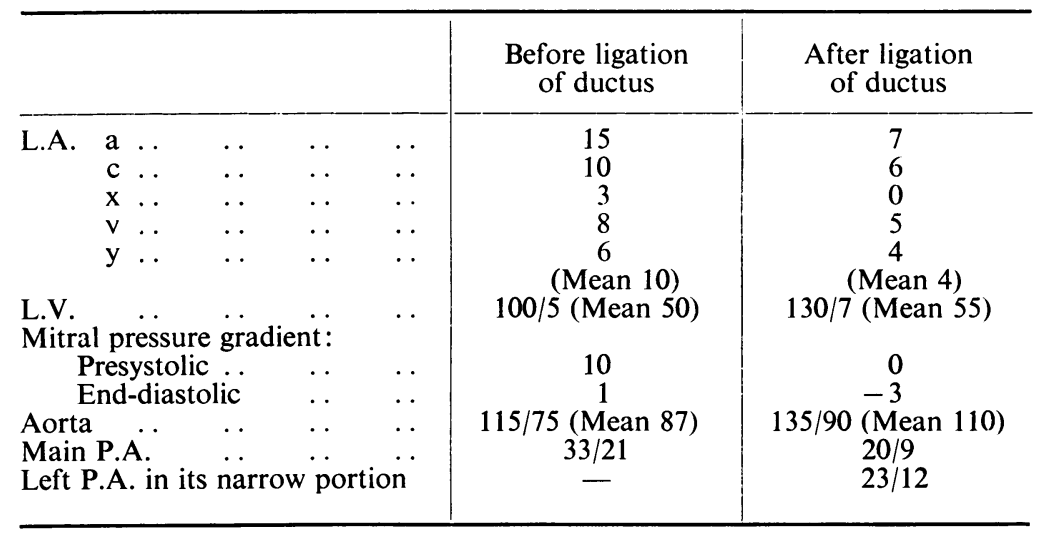

These pressures, taken before and after ligation of the persistent ductus, indicated that the lesion at the mitral valve was one of almost pure incompetence, that the mild pulmonary arterial hypertension was entirely hyperkinetic, and that there was no pressure gradient across the narrowed zone of the left pulmonary artery. The dominant "a" wave shown in the first left atrial trace

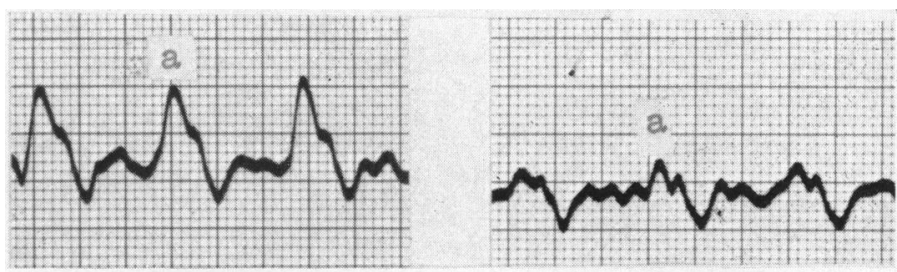

Fig. 4.-Prominent " $a$ " wave in left atrial trace before ligation of ductus (left panel). Disappearance of dominant "a" wave after ligation of ductus (right panel). (Fig. 4), despite almost pure mitral incompetence, was due to torrential flow as it disappeared after closing the ductus. The lesions found at thoracotomy were:-

1. Large persistent ductus arteriosus, of almost window type, with mild hyperkinetic pulmonary arterial hypertension.

2. Mitral incompetence.

3. Hypoplasia of left pulmonary artery and its lobar and segmental branches.

4. Emphysema of left upper lobe and absent pigment in left lung.

Treatment. The ductus was doubly ligated with flossed silk. This eliminated the ductus thrill, but not that due to the mitral incompetence; it lowered the pulmonary arterial pressure and raised the systolic and diastolic blood pressures from $115 / 70$ to $120 / 90$. The dominant "a" wave disappeared from the left atrial trace (Fig. 4). Convalescence was uneventful, and the patient was discharged on 23/8/58.

Subsequent Course. The patient's exercise tolerance improved dramatically after the operation and when she was seen on $9 / 7 / 60$ she declared that she had no disability or symptoms of any kind. She had completed a course in shorthand and typing, and was doing full time work as a clerk. On examination there was no cyanosis and no evidence of congestive failure. There were no physical signs of either a persistent ductus arteriosus or mitral stenosis, and the signs of mitral incompetence were much less marked. The blood pressure was 125/80. 
Radiological examination (Fig. 2) showed a great reduction in the size of the heart and pulmonary artery. The pleonæmia of the right lung was only slight, and the vascularity of the left lung appeared to be slightly improved. An electrocardiogram taken on 24/7/59 showed less left atrial hypertropy and disappearance of the left ventricular strain pattern.

Post-operative Pulmonary function tests and Bronchography. Bronchography (Fig. 3) showed absence of filling of the terminal branches of the left bronchial tree, and slight dilatation and irregularity of the segmental and smaller bronchi. The right bronchial tree was normal. The M.B.C. (indirect) was 59 1/min., and bronchospirometry showed severe impairment of ventilation and oxygen uptake on the left side. The findings were as follows.

\begin{tabular}{l|c|c}
\hline & \multicolumn{1}{|c|}{ Right lung } & Left lung \\
\cline { 1 - 2 } $\begin{array}{l}\text { Oxygen uptake } \ldots \\
\text { Minute ventilation }\end{array}$ & $\begin{array}{l}198 \mathrm{ml} . / \mathrm{min} .(86 \%) \\
4.401 / \mathrm{min} .(79 \%)\end{array}$ & $\begin{array}{c}32 \mathrm{ml} . / \mathrm{min} .(14 \%) \\
1.201 / \mathrm{min} .(21 \%)\end{array}$ \\
\hline
\end{tabular}

\section{Summary}

The salient feature of this case was the superimposing of rheumatic heart disease on a congenital heart lesion, in association with hypoplasia of the left pulmonary artery and transradiancy of the left lung.

The presence of a large patent ductus arteriosus modified the mitral signs. Its closure eliminated the left-to-right shunt; also the clinical signs suggestive of mitral stenosis disappeared while the rate of mitral regurgitation was diminished.

The abnormality of the left pulmonary artery and lung was thought to be developmental. This view is supported by the association with other developmental anomalies and by the absence of pigment in the lung. Darke et al. (1960), however, suggest that a pneumonic episode in early life, as occurred in our patient (side not known), might cause a ventilatory deficiency compensated by reduced circulation.

Surgery converted a chronic invalid into an individual fit enough to work full-time in a clerical capacity, who now declares that she is free from symptoms despite severe impairment of ventilation and oxygen uptake in the left lung.

Our grateful thanks are due to Dr. J. C. Meeks and Dr. G. de B. Hinde for their radiological studies, to Dr. A. J. Thomas for the electrocardiograms and phonocardiograms, and for his findings at cardiac catheterization, and to Dr. L. R. West for the lung function studies. Our thanks are also due to the nursing staff of Llandough Hospital for their expert nursing, to Miss Lyn Reynolds for recording the pressures at thoracotomy, and to Mr. R. Marshall for preparing the illustrations.

\section{Reference}

Darke, C. S., Crispin, A. R., and Snowden, Beryl, S. (1960). Thorax, 15, 74. 